\title{
Word recognition memory in adults with attention-deficit/ hyperactivity disorder as reflected by event-related potentials
}

\section{Vanessa Prox-Vagedes ${ }^{*}$, Stefanie Steinert ${ }^{\dagger}$, Yuanyuan Zhang, Mandy Roy, Wolfgang Dillo, Hinderk M. Emrich, Detlef E. Dietrich and Martin D. Ohlmeier}

Department of Psychiatry, Socialpsychiatry and Psychotherapy, Hannover Medical School, Hannover, Germany

\section{Edited by:}

Hans-Jochen Heinze, University of

Magdeburg, Germany

\section{Reviewed by:}

George R. Mangun, University of

California Davis, USA

Lioba Baving, Zentrums für Integrative

Psychiatrie, Germany

*Correspondence:

Vanessa Prox-Vagedes, Department for

Psychiatry, Socialpsychiatry and

Psychotherapy, Medizinische

Hochschule Hannover, Carl-Neuberg-

Str. 1, 30625 Hannover, Germany.

e-mail:prox-vagedes.vanessa@

mh-hannover.de

${ }^{\dagger}$ Vanessa Prox-Vagedes and Stefanie Steinert have contributed equally to this work.
Objective: Attention-deficit/hyperactivity disorder (ADHD) is increasingly diagnosed in adults. In this study we address the question whether there are impairments in recognition memory. Methods: In the present study 13 adults diagnosed with ADHD according to DSM-IV and 13 healthy controls were examined with respect to event-related potentials (ERPs) in a visual continuous word recognition paradigm to gain information about recognition memory effects in these patients. Results: The amplitude of one attention-related ERP component, the N1, was significantly increased for the ADHD adults compared with the healthy controls in the occipital electrodes. The ERPs for the second presentation were significantly more positive than the ERPs for the first presentation. This effect did not significantly differ between groups. Conclusion: Neuronal activity related to an early attentional mechanism appears to be enhanced in ADHD patients. Concerning the early or the late part of the old/new effect ADHD patients show no difference which suggests that there are no differences with respect to recollection and familiarity-based recognition processes.

Keywords: attention-deficit/hyperactivity disorder, adults, word recognition, event-related potentials, memory

\section{INTRODUCTION}

According to DSM-IV attention-deficit/hyperactivity disorder (ADHD) comprises the symptoms of an attention-deficit, hyperactivity, and a disturbance of impulse control. ADHD is nowadays understood as a genetically determined dysfunction of the dopamine and noradrenergic catecholamine system (Ernst et al., 1998; Faraone and Biederman, 1998; Dougherty et al., 1999; Dresel et al., 2000; Krause et al., 2003). The first symptoms of this disorder occur during childhood. From 1 to $9.5 \%$ of the entire child population may be affected by ADHD (Barkley, 1998). Kessler et al. (2006) estimated the prevalence of current adult ADHD to be $4.4 \%$.

Naturally, symptoms can modify in adulthood, so that socio-economical problems like a higher rate of accidents (Barkley et al., 1993) and a limited ability to work additionally occur. Furthermore, ADHD in adults is thought to be a risk factor for addiction to drugs (Wilens, 2004). Stimulating drugs like methylphenidate have been available as a therapy option over the past years and are said to improve the symptoms of ADHD. This may be due to a reduction in problems associated with norepinephrine and dopamine dysfunctions (Solanto, 2002). A disruption of right hemispheric attentional mechanisms may be related to diminished right hemispheric frontostriatal catecholamine activity (Carter et al., 1995).

The major deficits in ADHD are said to concern the perception and processing of information (Armstrong et al., 2001). In continuous performance tests (CPT) ADHD patients show more mistakes of commission, i.e., mistakes generated by impulsiveness, than mistakes of omission. Furthermore, ADHD patients show slower reaction times (RTs) than healthy controls. This may be a result of deficits in intention, planning, processing, and reacting to a new situation. These deficits are closely related to the working memory and the executive functions of the frontal cortex (Denckla, 1996). In an actual study of Krauel et al. (2010) using transcranial sonography an increased vulnerability of the nigrostriatal system in ADHD children was found. Furthermore there was a hyperechogenicity of the substantia nigra which they interpreted to be a possible correlate of a specific subgroup of ADHD. As another explanation the hyperechogenicity may be functionally related to differences in reward processing, learning, and motor function. This model could be another possible explanation for the symptoms of ADHD patients.

As far as we know, no studies have dealt directly with recognition in an event-related potential (ERP) task with ADHD adults. In the current study we address the question of whether there are significant differences between adult patients who suffer from ADHD and healthy controls with respect to the neural correlates of recognition, as quantified by ERPs in a continuous word recognition memory task. This topic is of great interest because most of the research work conducted so far has concentrated on children and did not have recognition as the main research theme.

Event-related potentials are small voltage fluctuations that can be recorded non-invasively from the human scalp. Different components have been described that are related to certain cognitive functions. Changes in these components can be used to specify cognitive dysfunctions in neuropsychiatric disorders (Münte, 2000).

Consequently, ERPs have been shown to be sensitive to memory processes (Johnson, 1995; Rugg, 1995b). Explicit memory processes for words have been examined by presenting and repeating words after some intervening items, with the subjects' task being to discriminate between newly presented and repeated words. Rugg and Nagy (1989) and Rugg et al. (1992) have shown that under these conditions, words evoke a series of negative and positive ERP 
components, which are more positive for repeated words, beginning approximately $200 \mathrm{~ms}$ after word presentation, involving most parts of the scalp. This effect is partially caused by a modification of the negative N400 component and the positive late positive component (LPC, P300), but has been termed the "old/new effect" to avoid premature identification of the effect with other ERP components (Rugg, 1995a,b; Rugg et al., 1996, 1997).

The late part of the old/new effect which is parietally pronounced appears to be influenced by the "conscious recollection" of the stimuli, e.g., of words (Rugg, 1995b; Rugg et al., 1996) and their frequency of occurrence (Rugg and Doyle, 1994). Dual process theories of memory posit that recognition judgments can be based on two different types of information: familiarity and recollection (Yonelinas, 1994). Curran (2000) stated that the FN400 ERP component (300-500 ms) in the spatiotemporal regions varied with the familiarity of words, whereas the parietal component (400-800 ms) was associated with the recollection of plurality. Differences in the timing and spatial topography of the FN400 and the parietal effects were interpreted as supporting the view that familiarity and recollection arise from distinct neurocognitive processes.

In our experiment we used a previously established word recognition ERP-paradigm (Dietrich et al., 2001) to investigate the influence of recognition on neural processing in non-medicated ADHD patients and controls in a continuous word recognition ERP-experiment. Our hypothesis was that ADHD adults who suffer from difficulties in focusing on a task could also be impaired in concentrating on a task in which they have to differ between new and old stimuli which could be a hint to impairments in ADHD adults in recognition and working memory processes.

\section{MATERIALS AND METHODS SUBJECTS}

Twenty German native speaking adults who fulfilled the DSM-IV criteria (American Psychiatric Association, 1994) for the diagnosis of ADHD were included. The Wender-Utah-Rating Scale, WURS, German version (Retz-Junginger et al., 2002) and the Conners'ADHD Rating Scales (CAARS; Conners et al., 1998) were also applied. Seven of these patients were excluded due to excessive eye-blink artifacts during the ERP recording session. Many ADHD patients have problems with eye-blinking or saccadic eye movements, due to hyperactivity (Munoz et al., 2003). The comparatively small group size and the consequently high drop out rate were accepted as being necessary to ensure that only the best ERP recordings were worked with.

The patients were examined without medication. Medicated patients stopped taking their medication at least 3 weeks before the examination to be sure that the drug was fully washed out. Patients with a comorbid current psychiatric diagnosis, drug abuse, medical, or neurological disorder, including tics or Tourette's syndrome, were excluded from the study.

The patient group consisted of 13 people diagnosed with ADHD (seven women and six men, aged 20-48 years, mean age 31.2). Thirteen healthy controls (seven women and six men, aged 20-56 years, mean age 32.2) were recruited from the student population and the staff of Hannover Medical School and were matched with respect to age, sex, and years of education. The study was approved by the local ethics committee and written informed consent was obtained from all participants.

\section{STIMULI AND PROCEDURE}

The stimuli (180 German verbs and 300 nouns) were compiled using a statistical thesaurus containing word frequency (Meier, 1967). They were presented at the fixation point on a computer monitor located $110 \mathrm{~cm}$ from the subject. The background of the video monitor was maintained in a uniform dark blue while the words were presented in white. Words contained 4-11 letters and each word was presented for $300 \mathrm{~ms}$, with a mean presentation rate of one word every $2.0 \pm 0.3 \mathrm{~s}$. Most words were repeated with an inter-item lag between the first and second presentation of 10-15 items. The probability of a second appearance in general was $40 \%$.

The subjects were tested while seated in a comfortable chair in a darkened and sound-attenuated room. They were instructed to fixate a central point on the video monitor, to relax when performing the task, and to avoid body movements, blinking or other eye movements. Giving equal importance to speed and accuracy, the subjects had to decide whether each word was presented for the first ("new") or the second ("old") time. The response buttons were positioned beneath each thumb. Half of the subjects had to push the right button for "new" words and the left button for repeated ("old") words; the other subjects vice versa. The words were presented in five blocks containing 90 words each, interrupted by a short break of about 1-2 $\mathrm{min}$.

\section{RECORDING AND QUANTIFICATION}

An EEG was recorded from all 19 positions of the International 10-20 System (Klem et al., 1999) via electrodes in an elastic cap (Electro-Cap International) referenced to a right mastoid electrode affixed to the skin with an adhesive collar. Additional electrodes were located laterally and beneath the right eye to record the EOG, which was to detect and reject signals resulting from eye-blinks.

The biosignals were amplified with a bandpass of $0.01-100 \mathrm{~Hz}$, digitized on-line with $4 \mathrm{~ms}$ resolution and stored on a hard disk. Artifact-rejection procedures were performed to reject trials contaminated with blinks (eye channels, maximum amplitude method), eye movements, muscle potentials, movement artifacts, or amplifier saturation. In addition, trials with incorrect behavioral responses were also excluded from the averages. EEG-signals were averaged off-line for an epoch length of $1000 \mathrm{~ms}$, beginning $100 \mathrm{~ms}$ before stimulus presentation. The resulting waveforms were quantified by mean amplitude measures relative to a 100 -ms prestimulus baseline, separately for the following time windows: $110-190 \mathrm{~ms}$ poststimulus (measuring the N1); 230-450 and 500-630 ms poststimulus (measuring early and late parts of the old/new effect).

\section{STATISTICAL EVALUATION}

Data were analyzed using repeated measures analysis of variance (ANOVAs) using a 5\% confidence level and were conducted separately for the occipital and temporal electrodes $(\mathrm{O} 1, \mathrm{O} 2)$ in the time range of $110-190 \mathrm{~ms}$ (referring to the N1), for the frontal and temporal electrodes (F3, F4; T5, T6) in the time range of 230 $450 \mathrm{~ms}$ (referring to the early old/new effect), and for the temporal and parietal electrodes (T5, T6; P3, P4) in the time window of 500-630 ms (referring to the late old/new effect). The analysis was computed with the factors group (controls vs. patients) and repetition (first vs. second presentation). The factor group was treated as a between group variable, whereas the other factor was 
a within-group factor. The behavioral performance was quantified by calculating RTs (ms) and hit rates (HR, \%) for the correct detection of first and second presentation.

The $p$-values were corrected by the Greenhouse-Geisser procedure wherever applicable.

\section{RESULTS \\ BEHAVIORAL RESULTS \\ Reaction time}

The RTs to words that were presented twice were longer in both groups [factor repetition: $F(1,24)=55.44 ; p<0.0001$ : $560 \pm 77$ vs. $664 \pm 40 \mathrm{~ms}$ for the subjects and $573 \pm 76 \mathrm{vs} .636 \pm 70 \mathrm{~ms}$ for the controls]. No significant differences were found between groups for the RTs [no main effect of the factor group: $F(1,24)=0.09$; $p=0.77]$. There was also no significant interaction of the factors group and repetition: $F(1,24)=3.29 ; p=0.08$.

\section{Hit rate}

Both groups showed a weaker performance in the second presentation in contrast to the first presentation [factor repetition: $F(1,24)=16.15 ; p<0.0001: 93.8 \pm 11.3$ vs. $78.4 \pm 15.3 \%$ for the controls and $97.8 \pm 2.2$ vs. $84.6 \pm 15.3 \%$ for the patients]. No general difference was found between groups for the HR [effect of the factor group analysis: $F(1,24)=1.73 ; p=0.20]$. Also there was no significant interaction of the factors group and repetition: $F(1,24)=0.10 ; p=0.76$.

\section{EVENT-RELATED POTENTIALS}

Figure 1 shows the grand mean ERPs for the patients and the control group for the first and second presentation of the words. In the time range of greater than $100 \mathrm{~ms}$ ERPs are more negative for the patients in contrast to the controls in the electrodes O1/O2 and T5. The late old/new effect is more negative for the first presentation than the second presentation, in both the patients and the controls. This is demonstrated by the electrodes $\mathrm{P} 3 / \mathrm{P} 4$.

The N1 was significantly different at the electrodes $\mathrm{O} 1 / \mathrm{O} 2$ between groups in the time window from 110 to $190 \mathrm{~ms}$ [factor group: $F(1,24)=5.22 ; p=0.031]$. The ERP at $\mathrm{O} 1$ showed a significant difference in the factor group: $[F(1,24)=8.15 ; p=0.009]$, but no significance for $\mathrm{O} 2$. There was no significant interaction of the factors group and repetition for the electrodes O1/O2: $[F(1,24)=1.72$; $p=0.20]$. For the electrodes $\mathrm{O} 1 / \mathrm{O} 2$ the factor repetition was not significant $[F(1,24)=1.69 ; p=0.21]$.

In the within-group ANOVA the factor repetition revealed a significant old/new effect in a time window from 230 to $450 \mathrm{~ms}$ for the electrodes F3/F4 $[F(1,24)=35.53 ; p=0.00]$ and also for the electrodes T5/T6 $[F(1,24)=9.11 ; p=0.006]$. The between groups ANOVA showed no significant difference for the early part of the old/new effect in a time window from 230 to $450 \mathrm{~ms}$ for the electrodes F3/F4 [factor group: $F(1,24)=0.14 ; p=0.72$ ] and T5/ T6 [factor group: $F(1,24)=3.16 ; p=0.09$ ]. There was no interaction of the factors group and repetition for the electrodes F3/F4 $[F(1,24)=0.23 ; p=0.63]$ or T5/T6 $[F(1,24)=1.32 ; p=0.26]$.

The late part of the old/new effect was significant in a time window from 500 to $630 \mathrm{~ms}$ for the electrodes P3/P4 [factor repetition was significant for the electrodes $\mathrm{P} 3 / \mathrm{P} 4 F(1,24)=4.69$; $p=0.04]$ and for the single electrodes P3 $[F(1,24)=56.57$; $p=0.00]$ and $\mathrm{P} 4[F(1,24)=12.16 ; p=0.002]$. There was no significant difference for the late part of the old/new effect for the electrodes T5/T6.

For the late part of the old/new effect in a time window from 500 to $630 \mathrm{~ms}$ the between groups ANOVA showed no significant difference for the factor group for the electrodes P3/P4 $[F(1,24)=1.31$; $p=0.27]$ and only a tendency toward significance for the electrodes T5/T6 [factors group: $F(1,24)=3.83 ; p=0.06$ ].

There was no significant interaction of the factors group and repetition for the electrodes $\mathrm{P} 3 / \mathrm{P} 4[F(1,24)=0.76 ; p=0.39]$ and T5/T6 $[F(1,24)=1.98 ; p=0.17]$.

\section{DISCUSSION}

One finding of this study was the higher amplitude of the N1 in the patient group. Another finding was that there was no statistically significant difference between the patient and the control group in the early and in the late part of the old/new effect. No statistically relevant difference was found between $\mathrm{HR}$ and RT in either group.

At first we found that the N1 component was elicited more strongly in the negative direction in the patient group than in the control group for this paradigm. This does not concern recognition memory but shows an enhanced neuronal activity in the ADHD group in this time window. Typically, the N1 is evoked in paradigms with a geometric component. So the N1 is thought to index spatial or selective attention (Hillyard and Anllo-Vento, 1998). Maybe the ADHD patient group has to focus more strongly on the selective component. This would explain the elevated N1, also in a word recognition paradigm. This theory is supported by similar findings with ADHD adults in a Go/Nogo paradigm in our previous studies. We found that ADHD adults possibly "shifted" more attention to the spatial component of the task to avoid making errors (Prox et al., 2007).

Consistent with our finding of an activated occipital region are also the findings of Schweitzer et al. (2000). The authors found changes in the regional cerebral blood flow in men with ADHD which were more widespread and primarily located in the occipital region in a PET study with a working memory test. They interpreted this as compensatory mental and neural strategies by subjects with ADHD in response to a disrupted ability to inhibit attention to nonrelevant stimuli. Barry et al. (2009) found a globally enhanced P2 and reduced N2 amplitudes to auditory targets and no differences in target P3 together with topographic differences in an N1 to auditory targets in an intermodal oddball-task in a study with 18 young ADHD males and controls. They interpreted these results in terms of early sensory-processing impairments in adults with ADHD, which were said to be partially overcome through effortful processing, as reflected in the later endogenous ERP components. An impairment in early sensory-processing could be another possible explanation for the finding of the elevated $\mathrm{N} 1$ in our word recognition paradigm.

Curran (2004) described the early old/new effect to be related to familiarity (300-500 ms, anterior). In our study the early part of the old/new effect showed no difference between ADHD adults and healthy controls, suggesting that there are no differences between the two groups in recognition processes related to familiarity.

Another finding of our study is that there are also no differences in the late part of the old/new effect, either in the temporal or in the parietal sites. Curran (2004) interpreted the late old/new effect 


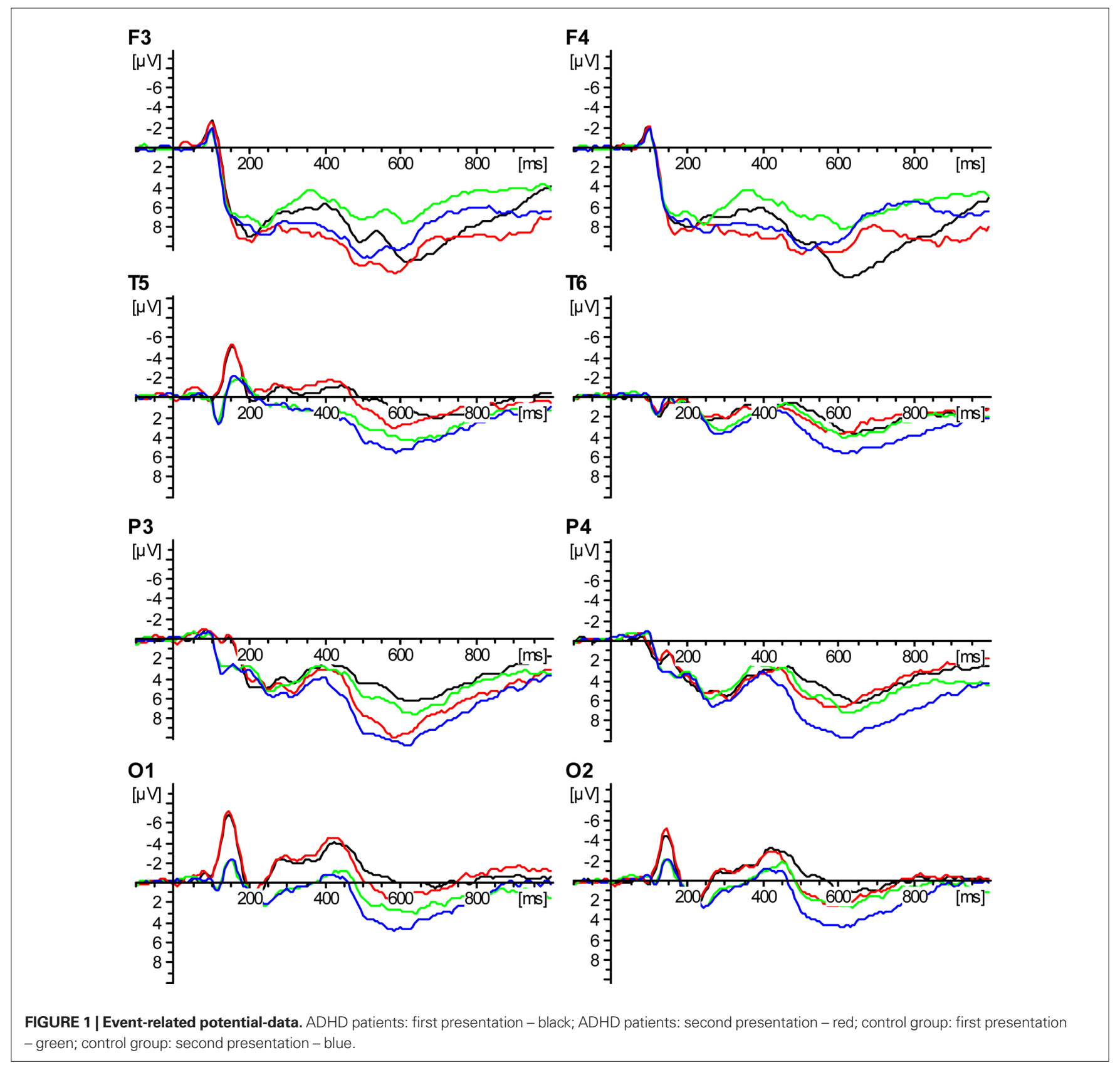

as being related to recollection (400-800 ms, parietal). In our study there was no statistical difference between the two groups for the late part of the old/new effect, which might suggest that there are no differences in recollection processes in ADHD adults in contrast to healthy controls.

Also interesting in this context is a study of Rugg et al. (1996) who examined healthy subjects with ERPs. The subjects had to discriminate between old and new words. In addition, for every word that was judged old, the subjects were advised to recall the word with which it was associated in the study. A positive shift for words which were correctly judged to be old and for which the associate was correctly recalled was found at temporo-parietal electrodes and lateralized to the left hemisphere. They interpreted this finding as reflecting neural activity associated with recollection of specific past episodes. As we found no differences between the ADHD group and the control group, these findings underline the theory that there are no differences in recollection processes in either group.

The old/new effect is also suggested to reflect memory processes of the medial temporal lobe system including the hippocampus and amygdala and their projections into, e.g., prefrontal and parietal cortical areas (Rugg et al., 1991, 1996, 1998; Fernandez et al., 1998). Context integration processes are a major task of the central processor of the working memory model which may influence different steps/subsystems of memory processing via "directing attentional sources" (Baddeley, 1992). 
Wolf et al. (2008) found a lower connectivity in the bilateral ventrolateral prefrontal cortex, the anterior cingulated cortex, the superior parietal lobule, and the cerebellum in ADHD adults compared with healthy control subjects in a f-MRT study with a parametric verbal working memory paradigm. They concluded that their findings suggest both regional brain activation deficits as well as functional connectivity abnormalities of the anterior cingulate and the parietal cortex in ADHD adults during working memory processing.

Our ERP data do not appear to disclose an impairment of memory processes in adult ADHD. The paradigm we used is not suited to drew a conclusion in this direction. If it was there had to be differences because problems with the working memory are a core deficit in ADHD (Barkley, 1997).

Our results did not show statistical differences between the two groups in HR or RTs. However, one might expect significant statistical differences in the behavior data between ADHD patients and the control group, especially as Barkley (1997) describes the working memory to be a core deficit in ADHD. Yong-Liang et al. (2000) found fewer correct responses in a Go/Nogo task with ADHD boys compared with a control group. In this respect our findings are surprising because not only the behavior data but also the early old/ new effect and the late old/new effect do not reveal significance in our study. This might support the theory that ADHD adults put a "hyperfocus" on the task to compensate for their lacking concentration when they are interested in a task (Krause and Krause, 2005). In this context this could mean that the ADHD people were motivated to achieve good results because they were in a test situation. Certainly this result might also be argued as a lack of motivation in the control group.

\section{REFERENCES}

American Psychiatric Association. (1994). DSM-IV Diagnostic Criteria of the Attention Deficit-/Hyperactivity Disorder. Washington, DC: American Psychiatric Association.

Armstrong, C. L., Hayes, K. M., and Martin, R. (2001). Neurocognitive problems in attention deficit disorder. Alternative concepts and evidence for impairment in inhibition of selective attention. Ann. N. Y. Acad. Sci. 931, 196-215.

Baddeley, A. (1992). Working memory. Science 255, 556-559.

Barkley, R. A. (1997). Behavioral inhibition, sustained attention, and executive functions: constructing a unifying theory of ADHD. Psychol. Bull. 121,65-94.

Barkley, R. A. (1998). Attention-deficit hyperactivity disorder. Sci. Am. 279, 66-71.

Barkley, R. A., Guevremont, D. C., Anastopoulos, A. D., DuPaul, G. J., and Shelton, T. L. (1993). Driving-related risks and outcomes of attention deficit hyperactivity disorder in adolescents and young adults: a 3- to 5-year followup survey. Pediatrics 92, 212-218.

Barry, R. J., Clarke, A. R., McCarthy, R., Selikowitz, M., Brown, C. R., and

Also the RTs in the two groups did not achieve a statistically relevant difference. The ADHD adults merely showed faster RTs in response to new words and slower RTs in the answers to old words. We had hypothesized that the RTs were in general faster because of the high impulsivity of ADHD patients. Cao et al. (2008) found a larger RT variability in a performing task for ADHD boys in contrast to healthy controls. One might argue that ADHD adults needed more time to answer to words they did not clearly remember as being old or recognized as new. However there was no statistical relevant difference between patients and controls.

One limitation of our study is the small sample size of only 13 ADHD patients and 13 controls. Initially we examined 20 patients but had to exclude seven due to excessive eye-blink artifacts. ERPs are affected by movements, e.g., eye-blinking which is difficult in a study with ADHD patients who also show symptoms of hyperactivity. Maybe a greater sample size would have disclosed differences between patients and controls. Further studies should work with a greater sample size to substantiate the findings of this study.

Another limitation is that we did not use neuroimaging techniques. Future studies with ERPs concerning memory should be planned in connection with, e.g., MRI studies. This would offer the possibility to compare neurophysiological data with structural analyses.

In conclusion, the present ERP data do not show a difference between ADHD adults and healthy controls in word recognition regarding both recollection processes and familiarity-based recognition processes, and suggest that ADHD patients are not restricted in this respect.

Future studies should substantiate these findings and further investigate the memory processes of ADHD children and ADHD adults with respect to a treatment with drugs.

is relevant to learning disability and attention-deficit hyperactivity disorder? J. Dev. Behav. Pediatr. 17, 114-119. Dietrich, D. E., Waller, C., Johannes, S., Wieringa, B. M., Emrich, H. M., and Munte, T. F. (2001) Differential effects of emotional content on event-related potentials in word recognition memory. Neuropsychobiology 43, 96-101.

Dougherty, D. D., Bonab, A. A., Spencer, T. J., Rauch, S. L., Madras, B. K., and Fischman, A. J. (1999). Dopamine transporter density in patients with attention deficit hyperactivity disorder. Lancet 354, 2132-2133.

Dresel, S., Krause, J., Krause, K. H., LaFougere, C., Brinkbaumer, K., Kung, H. F., Hahn, K., and Tatsch, K. (2000). Attention deficit hyperactivity disorder: binding of [99mTc]TRODAT-1 to the dopamine transporter before and after methylphenidate treatment. Eur. J. Nucl. Med. 27, 1518-1524.

Ernst, M., Zametkin, A. J., Matochik, J. A., Jons, P. H., and Cohen, R. M. (1998). DOPA decarboxylase activity in attention deficit hyperactivity disorder adults. A [fluorine-18] fluorodopa positron emission tomographic study. J. Neurosci. 18, 5901-5907.
Faraone, S. V., and Biederman, J. (1998). Neurobiology of attention-deficit hyperactivity disorder. Biol. Psychiatry 44, 951-958.

Fernandez, G., Weyerts, H., Tendolkar, I., Smid, H. G., Scholz, M., and Heinze, H. J. (1998). Event-related potentials of verbal encoding into episodic memory: dissociation between the effects of subsequent memory performance and distinctiveness. Psychophysiology 35, 709-720.

Hillyard, S. A., and Anllo-Vento, L. (1998). Event-related brain potentials in the study of visual selective attention. Proc. Natl. Acad. Sci. U.S.A. 95, 781-787.

Johnson, R. (1995). “Event-related potential insights into the neurobiology of memory systems," in Handbook of Neuropsychology, eds J. C. Baron and J. Grafman (Amsterdam: Elsevier) 135-164.

Kessler, R. C., Adler, L., Barkley, R., Biederman, J., Conners, C. K., Demler, O., Faraone, S. V., Greenhill, L. L., Howes, M. J., Secnik, K., Spencer, T., Ustun, T. B., Walters, E. E., and Zaslavsky, A. M. (2006). The prevalence and correlates of adult ADHD in the United States: results from 
the National Comorbidity Survey Replication. Am. J. Psychiatry 163, 716-723.

Klem, G. H., Luders, H. O., Jasper, H. H., and Elger, C. (1999). The ten-twenty electrode system of the International Federation. The International Federation of Clinical Neurophysiology. Electroencephalogr. Clin. Neurophysiol. 52(Suppl.), 3-6.

Krauel, K., Feldhaus, H. C., Simon, A., Rehe, C., Glaser, M., Flechtner, H. H., Heinze, H. J., and Niehaus, L. (2010). Increased echogenicity of the substantia nigra in children and adolescents with attentiondeficit/hyperactivity disorder. Biol. Psychiatry 68, 352-358.

Krause, J., and Krause, K. H. (2005). Aufmerksamkeits und Konzentrationsstörungen. In ADHS im Erwachsenenalter. Stuttgart: Schattauer, 46-54.

Krause, K. H., Dresel, S. H., Krause, J., la Fougere, C., and Ackenheil, M. (2003). The dopamine transporter and neuroimaging in attention deficit hyperactivity disorder. Neurosci. Biobehav. Rev. 27, 605-613.

Meier, R. (1967). Deutsche Sprachstatistik., Hildesheim: Olms.

Munoz, D. P., Armstrong, I. T., Hampton, K.A., and Moore, K. D. (2003). Altered control of visual fixation and saccadic eye movements in attention-deficit hyperactivity disorder. J. Neurophysiol. 90, 503-514.

Münte, T. F. (2000). "Event-related brain potentials in the study of human cognition and neuropsychology," in Handbook of Neuropsychology, eds F. Boller, J. Grafman, and G. Rizzolatti (Amsterdam: Elsevier), 139-235.
Prox, V., Dietrich, D. E., Zhang, Y., Emrich, H. M., and Ohlmeier, M. D. (2007). Attentional processing in adults with ADHD as reflected by event-related potentials. Neurosci. Lett.419, 236-241.

Retz-Junginger, P., Retz, W., Blocher, D., Weijers, H. G., Trott, G. E., Wender, P. H., and Rossler, M. (2002). Wender Utah rating scale. The short-version for the assessment of the attentiondeficit hyperactivity disorder in adults. Nervenarzt 73, 830-838.

Rugg, M. D. (1995a). "ERP studies of memory" in Electrophysiology of Mind, Event-Related Brain Potentials and Cognition, eds M. D. Rugg and M. G. H. Coles (Oxford: Oxford University Press), 130-170.

Rugg, M. D. (1995b). "Event-related potential studies of human memory," in The Cognitive Neurosciences, ed. M. S. Gazzaniga (Cambridge: Bradford Book), 789-801.

Rugg, M. D., Brovedani, P., and Doyle, M. C. (1992). Modulation of eventrelated potentials (ERPs) by word repetition in a task with inconsistent mapping between repetition and response. Electroencephalogr. Clin. Neurophysiol. 84, 521-531.

Rugg, M. D., and Doyle, M. C. (1994). "Event-related potentials and stimulus repetition in direct and indirect tests of memory," in Cognitive Electrophysiology, eds H. J. Heinze, T. F. Münte, and G. R. Mangun(Boston: Birkhäuser), 124-148.

Rugg, M. D., Mark, R. E., Gilchrist, J., and Roberts, R. C. (1997). ERP repetition effects in indirect and direct tasks: effects of age and interitem lag. Psychophysiology 34, 572-586.

Rugg, M. D., and Nagy, M. E. (1989). Event-related potentials and rec- ognition memory for words. Electroencephalogr. Clin. Neurophysiol. 72, 395-406.

Rugg, M. D., Roberts, R. C., Potter, D. D., Pickles, C. D., and Nagy, M. E. (1991). Event-related potentials related to recognition memory. Effects of unilateral temporal lobectomy and temporal lobe epilepsy. Brain 114(Pt 5), 2313-2332.

Rugg, M. D., Schloerscheidt, A. M., Doyle, M. C., Cox, C. J., and Patching, G. R. (1996). Event-related potentials and the recollection of associative information. Brain Res. Cogn. Brain Res. 4 , 297-304.

Rugg, M. D., Walla, P., Schloerscheidt, A. M., Fletcher, P. C., Frith, C. D., and Dolan, R. J. (1998). Neural correlates of depth of processing effects on recollection: evidence from brain potentials and positron emission tomography. Exp. Brain Res. 123 $18-23$.

Schweitzer, J. B., Faber, T. L., Grafton, S. T., Tune, L. E., Hoffman, J. M., and Kilts, C. D. (2000). Alterations in the functional anatomy of working memory in adult attention deficit hyperactivity disorder. Am. J. Psychiatry 157, 278-280.

Solanto, M. V. (2002). Dopamine dysfunction in $\mathrm{AD} / \mathrm{HD}$ : integrating clini$\mathrm{cal}$ and basic neuroscience research. Behav. Brain Res. 130, 65-71.

Wilens, T. E. (2004). Impact of ADHD and its treatment on substance abuse in adults. J. Clin. Psychiatry 65(Suppl. 3), 38-45.

Wolf, R. C., Plichta, M. M., Sambataro, F., Fallgatter, A. J., Jacob, C., Lesch, K. P., Herrmann, M. J., Schonfeldt-Lecuona, C., Connemann, B. J., Gron, G., and
Vasic, N. (2008). Regional brain activation changes and abnormal functional connectivity of the ventrolateral prefrontal cortex during working memory processing in adults with attention-deficit/hyperactivity disorder. Hum. Brain Mapp. 30, 2252-2266.

Yonelinas, A. P. (1994). Receiver-operating characteristics in recognition memory: evidence for a dual-process model. J. Exp. Psychol. Learn. Mem. Cogn. 20, 1341-1354.

Yong-Liang, G., Robaey, P., Karayanidis, F., Bourassa,M.,Pelletier, G., and Geoffroy, G. (2000). ERPs and behavioral inhibition in a go/no-go task in children with attention-deficit hyperactivity disorder. Brain Cogn. 43, 215-220.

Conflict of Interest Statement: The authors declare that the research was conducted in the absence of any commercial or financial relationships that could be construed as a potential conflict of interest.

Received: 19April 2010; accepted: 04 March 2011; published online: 16 March 2011.

Citation: Prox-Vagedes V, Steinert S, Zhang Y, Roy M, Dillo W, Emrich HM, DietrichDE and Ohlmeier MD (2011) Word recognition memory in adults with attention-deficit/ hyperactivity disorder as reflected by eventrelated potentials. Front. Hum. Neurosci. 5:27. doi: 10.3389/fnhum.2011.00027 Copyright (c) 2011 Prox-Vagedes, Steinert, Zhang, Roy, Dillo, Emrich, Dietrich and Ohlmeier. This is an open-access article subject to an exclusive license agreement between the authors and Frontiers Media $S A$, which permits unrestricted use, distribution, and reproduction in any medium, provided the original authors and source are credited. 